\title{
Tangence
}

\section{Montréal, l'île lumière (La triste beauté du monde, de Mona Latif-Ghattas)}

\section{Huguette-Éna Lapitre}

Numéro 49, décembre 1995

Les littératures francophones de l'Afrique et des Antilles

URI : https://id.erudit.org/iderudit/025885ar

DOI : https://doi.org/10.7202/025885ar

Aller au sommaire du numéro

Éditeur(s)

Tangence

ISSN

0226-9554 (imprimé)

1710-0305 (numérique)

Découvrir la revue

Citer ce compte rendu

Lapitre, H.-É. (1995). Compte rendu de [Montréal, l'île lumière (La triste beauté du monde, de Mona Latif-Ghattas)]. Tangence, (49), 129-130.

https://doi.org/10.7202/025885ar d'utilisation que vous pouvez consulter en ligne.

https://apropos.erudit.org/fr/usagers/politique-dutilisation/ 


\title{
Montréal, l'île lumière
}

\section{Mona Latif-Ghattas, La triste beauté du monde, Montréal, Éditions du Noroît, 1993, 100 p.}

\author{
Je te regarde Montréal \\ D'aussi loin que remonte mon âge avec tes mots \\ Puisque tu parles et je comprends \\ "Concerto pour une île" (p. 100)
}

Il n'est pas toujours facile de saisir toutes les subtilités de l'imaginaire de Mona Latif-Ghattas qui voyage entre l'Occident et l'Orient, par le biais de titres originaux qui résonnent sous forme de chants gais ou tristes: de survie, d'oubli, de Genèse et d'avenir. Mais quand elle fixe noir sur blanc les images de Montréal, on croit se trouver devant une carte postale mouvante de beauté et de simplicité; on découvre "une île saisie dans le tournant de la lumière" (p. 99).

Sa fascination et son amour pour Montréal imprègnent sa description qui offre parfois des teintes de sensualité. Pour le plaisir des spectateurs émerveillés, cette ville

flirte avec la lumière, [charme] les éclaircies et les rayons Itout en se laissant courtiser par des] violons tziganes, des cymbales d'acier, des harpes angéliques ou des trompettes d'or. (p. 99)

Dans l'univers imaginaire de Mona Latif-Ghattas, ces moments magiques de contemplation semblent rivaliser avec le sentiment merveilleux que provoquent habituellement les contes de fées et certains rêves:

Je te regarde Montréal [...]

Je te vois te mouvoir et me dis que la magie n'est plus le privilège des contes et des rêves. (p. 99)

Au fil du poème "concerto pour une île", les divers paysages de Montréal se transforment "du lever au coucher des saisons". Dans une certaine "clarté diffuse",

[...] le Mont-Royal déploie ses ailes et plane au-dessus de la ville / [ . . ] la couronne de Saint-Joseph sous le soleil se change en un flambeau de procession / [...] les érables généreux 
multicolorent leurs parures et se dénudent pour tapisser les terres sèches des forêts / [...] le Saint-Laurent comme [...] un néon bleuté défie les brumes et les neiges [...]. (p. 99)

L'hiver, deuil des beaux jours, apporte la grisaille qui ternit les façades des rues de l'île lumière:

La tristesse dévale les monts des Laurentides et s'étale ahurie sur les plaines des cantons / [...] dans les jardins les écureuils ont figé leurs élans sur les branches raidies. (p. 22)

À Montréal, les saisons se suivent mais ne se ressemblent pas; les races se croisent et parfois se comprennent, les sexes s'affrontent pour l'égalité, dans un espace libre, "là ou s'affirme la différence comme un acquis de l'univers":

[...] j'ai grandi sur ton estrade libre

Où fondent certains fils barbelés de l'Orient

Où se fondent les races

Où s'affrontent les sexes $[. .$.$] (p. 100)$

Pour les gens d'ici et d'ailleurs Montréal, espace libre, lieu "d'exil ou de demeure" dévoile à Mona Latif-Ghattas le sens des images, des paysages et lui fait entendre la "musique d'une langue" qui vient de la source des mots:

mes lèvres frôlent et balbutient goûtant le suc des voix le jour des signes [...] à la douzième cadence de l'heure je Suis.

("Pavane sur un ailleurs flottant", p. 40)

Être poète à Montréal, loin d'une certaine "nuit orientale" et sentir l'Occident devenir tangible, palpable représente bien plus qu'un rêve pour l'écrivaine.

Même si on ne s'identifie pas toujours aux métaphores obsédantes qui évoquent un certain passé et parsèment l'univers imaginaire de l'auteure, les deux poèmes "Concerto pour une île" et "Quatorze flammes" rendent un beau et vibrant hommage à Montréal, "ville ouverte" sur le monde. À lire absolument!

\section{Huguette-Éna Lapitre}

